with, and the tables show that the age of greatest prevalence is about 15 , and that there is a great preponderance of females over males in those attacked. The percentage of association with hereditary syphilis varies between 30 (Siklosoi) and 92.5 (Ayres and Bossi), and with acquired syphilis between 3 and 12 .

Aetiology.-After giving at some length the views of Panas and Fournier, who considered the disease not as a direct manifestation of syphilis but simply as dyscrasic or parasyphilitic, the author passes to the evidence of the existence of the spirochaete within the cornea itself, and describes the observations of Morax, Stephenson, Greef and others, together with the experiments of Wagenmann in ligaturing the long posterior ciliary arteries and of Kester in ligaturing the venae vorticosae.

Histological reports by Virchow, Fuchs and Elschnig follow, and the author completes an excellent resumé of most of the thoughts and observations of writers from the time of Hutchinson till now. $\mathrm{He}$ concludes by saying: "notwithstanding diligent research and passionate discussion the question still remains for solution if interstitial keratitis is a degenerative process of trophic origin or a true manifestation of inflammation of the cornea."

Next follow the personal observations of the author, and a series of tables gives an account of 100 cases which have been carefully recorded and studied by him in the eye clinic of Rome.

Concluding Note.-After a consideration of the clinical observations, the results of serological and experimental investigations together with an examination of the various views of the aetiology and pathology of interstitial keratitis there emerges a typical form which differs in character from all other forms of interstitial infiltration of the cornea and which is always associated with syphilis, ordinarily hereditary, but sometimes acquired. It is intrinsically an inflammation of the corneal parenchyma with the characteristic stages of infiltration, vascularization, and resolution.

W. T. Holmes SPICER.

\title{
OBITUARY
}

\section{THOMAS BRITTIN ARCHER, I846-I924}

THE late Mr. Archer was the youngest child of the late Goodwyn Archer of Ely, Cambridgeshire. He was educated at "The King's School," Ely, and afterwards at the Grammar School, Ipswich. He was apprenticed in 1865 to the late Richard Jones, Medical Practitioner of Woodbridge, Suffolk, and from thence completed 
his medical studies at St. Bartholomew's Hospital, obtaining the qualification of M.R.C.S.

When the first Ophthalmic Ward of St. Bartholomew's Hospital was opened in November, $1870, \mathrm{Mr}$. Archer was appointed Ophthalmic House Surgeon, and served for a year. Subsequently he visited in rotation the principal ophthalmic hospitals in Brussels, Berlin, and Vienna, for a period of nearly three years. On his return in 1873 , he was appointed clinical assistant to the Central London Ophthalmic Hospital, and the Royal London Ophthalmic Hospital, and became surgeon to the former hospital in the same year. To this hospital he practically devoted all his energies for he neither cared for private practice nor sought after it. He became the senior surgeon in 1879 , and from that time as Chairman of the Medical Committee did all in his power to increase the efficiency of the hospital both as regards its structure and personnel.

On retiring at the age limit of 65 in 1911 , the members of the honorary staff and the committee presented him with a silver cup in recognition of his services, which he subsequently presented to the hospital as a Loving cup to be used at the Annual Dinner. About this time he gave up private practice entirely, and, became Chairman of the hospital at the most critical period of its history when its funds were at a low ebb and money had to be obtained to build a new institution. It is probable that if he had not come forward and filled the post of Chairman and Treasurer of the hospital at that time the new hospital would not have been built. During this time he attended the hospital daily, supervising the collection of the funds, etc.

On the outbreak of the War he once more became an active member of the staff helping daily to replace those members of the staff who had been called up on active service. $T_{0}$ show the appreciation of his services the Committee of Management called one of the wards in the new hospital the "Archer Ward."

Although he was an original member of the Ophthalmological Society of the United Kingdom, in latter years he did not often attend its meetings, but he always carefully perused the contents of its Transactions from cover to cover. When in active practice he was always abreast of the times in his speciality. From time to time he gave most interesting clinical lectures at the hospitai, but was adverse to their publication. He presented $£ 100$, the interest of which to form a prize for junior clinical assistants. In 1921, he resigned the Chairmanship of the hospital and retired into private life.

He died on January 24, 1924, of angina pectoris. He was fond of music and painting, and in his youth was an expert with both rod and gun. Under a somewhat critical manner he hid a generous, straightforward nature which endeared him to those who knew him well. 